Search > Results > Impact of expansion level ...

$$
\text { Full text at publisher }
$$

1 of $1>$

\section{Impact of expansion level on flowfield with sudden expansion at supersonic regimes}

By: Faheem, M (Faheem, Mohammed) 1, 3; Ridwan (Ridwan) ${ }^{2}$; Muneer, R (Muneer, Rayid) ${ }^{3}$; Delvi, HA (Delvi, Hamza Afser) ${ }^{4}$; Khan, SA (Khan, Sher Afghan) ${ }^{1}$

View Web of Science ResearcherID and ORCID (provided by Clarivate)

\section{MATERIALS TODAY-PROCEEDINGS}

$\begin{array}{lllll}\text { Volume: } & \text { Page: } 2775- & \begin{array}{l}\text { Special } \\ \text { Issue }\end{array} & \text { Part: } \\ 46 & 2782 & \mathrm{SI} & 7\end{array}$

DOI: $10.1016 /$ j.matpr.2021.02.575

Published: 2021

Document Type: Proceedings Paper

\section{Conference}

Meeting: 2nd International Conference on Smart and Sustainable Developments in Materials, Manufacturing and Energy Engineering (SME)

Location: Nitte, INDIA

Date: DEC 22-23, 2020

Sponsor: NMAM Inst Technol

\section{Abstract}

This paper aims to assess the control mechanism's efficiency and flow pattern in the pipe. The flow was investigated for Mach numbers $M=1.25,1.3,1.48,1.6$, $1.8,2.0,2.5$, and 3.0 for a step height of $3 \mathrm{~mm}$. The NPRs of the tests were from 11 to 3 . The flow revealed the minimum duct requirement for a given Mach number and NPR as L = 2D. Only some selected cases where control mechanism impacts considerably are presented. In most of the cases, the flow field was the same. There is a reversal in control in the flow field; only such cases are discussed. At low Mach numbers, the flow regulator raises the pressure, and for the rest of the Mach numbers, the control findings are to reduce the pressure except at NPR $=9$ at $M a c h M=3.0$,
Export $\vee$

Add To Marked List

\section{Citation Network}

In Web of Science Core Collection

0

Citations

Create citation alert

Cited References

19

View Related Records

You may also like...

Poojari, M; Shreyas, BS; Babu, BS; et al.

Design, analysis of steering system and front

suspension for an Electric All-Terrain vehicle MATERIALS TODAY-PROCEEDINGS

Sumayli, A;

Recent trends on bioimplant materials: $A$ review

MATERIALS TODAY-PROCEEDINGS

Prasad, CD; Lingappa, MS; Sachin, B; et al. Characterization and sliding wear behavior of CoMoCrSi plus Flyash composite cladding processed by microwave irradiation MATERIALS TODAY-PROCEEDINGS

Kumara, KSJ; Krishnamurthy, GN; Bhat, S; et al. Palladium metal embedded on mesoposrous graphene oxide as an efficient heterogeneous catalyst for Suzuki coupling reaction MATERIALS TODAY-PROCEEDINGS

Deshmukh, R; Sanap, S; Thakur, D; Theoretical modelling and experimental characterization of composite material for uln bone plate application 
a reversed trend. (C) 2021 Elsevier Ltd. All rights reserved. Selection and peer-review under responsibility of the scientific committee of the International Conference on Smart and Sustainable Developments in Materials, Manufacturing and Energy Engineering.

\section{Keywords}

Author Keywords: Sudden Expansion; Jet State; Supersonic Regime; Wall Pressure; Circular Duct; Microjets; Active Control

\section{Author Information}

Corresponding : Khan, Sher (corresponding Address Afghan author)

$\checkmark$ Int Islamic Univ Malaysia, Fac Engn, Dept Mech Engn, Kuala Lumpur, Malaysia

Addresses:

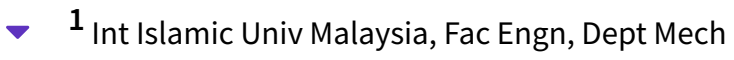

Engn, Kuala Lumpur, Malaysia

$\checkmark \quad \mathbf{2}$ Visvesvaraya Technol Univ, Dept Mech Engn,

Bearys Inst Technol, Mangaluru, India

- ${ }^{3}$ Visvesvaraya Technol Univ, Dept Mech Engn,

Coll Engn, Mangaluru, India

4 Raa Techno Mech \& Civil Works, Hassan, India

E-mail Addresses: sakhan@iium.edu.my

Categories/Classification

Research Areas: Materials Science

\section{+ See more data fields}

MATERIALS TODAY-PROCEEDINGS

See all

\section{Use in Web of Science}

Web of Science Usage Count
0

Last 180 Days

Learn more
0

Since 2013
This record is from:

Web of Science Core Collection

Conference Proceedings Citation Index Science (CPCI-S)

\section{Suggest a correction}

If you would like to improve the quality of the data in this record, please Suggest a correction

\section{Journal information}

\section{MATERIALS TODAY-PROCEEDINGS}

ISSN: 2214-7853

Current Publisher: ELSEVIER, RADARWEG 29, 1043 NX

AMSTERDAM, NETHERLANDS

Research Areas: Materials Science

Web of Science Categories: Materials Science, Multidisciplinary

\section{Cited References}

$$
\text { Showing } 19 \text { of } 19 \quad \text { View as set of results }
$$



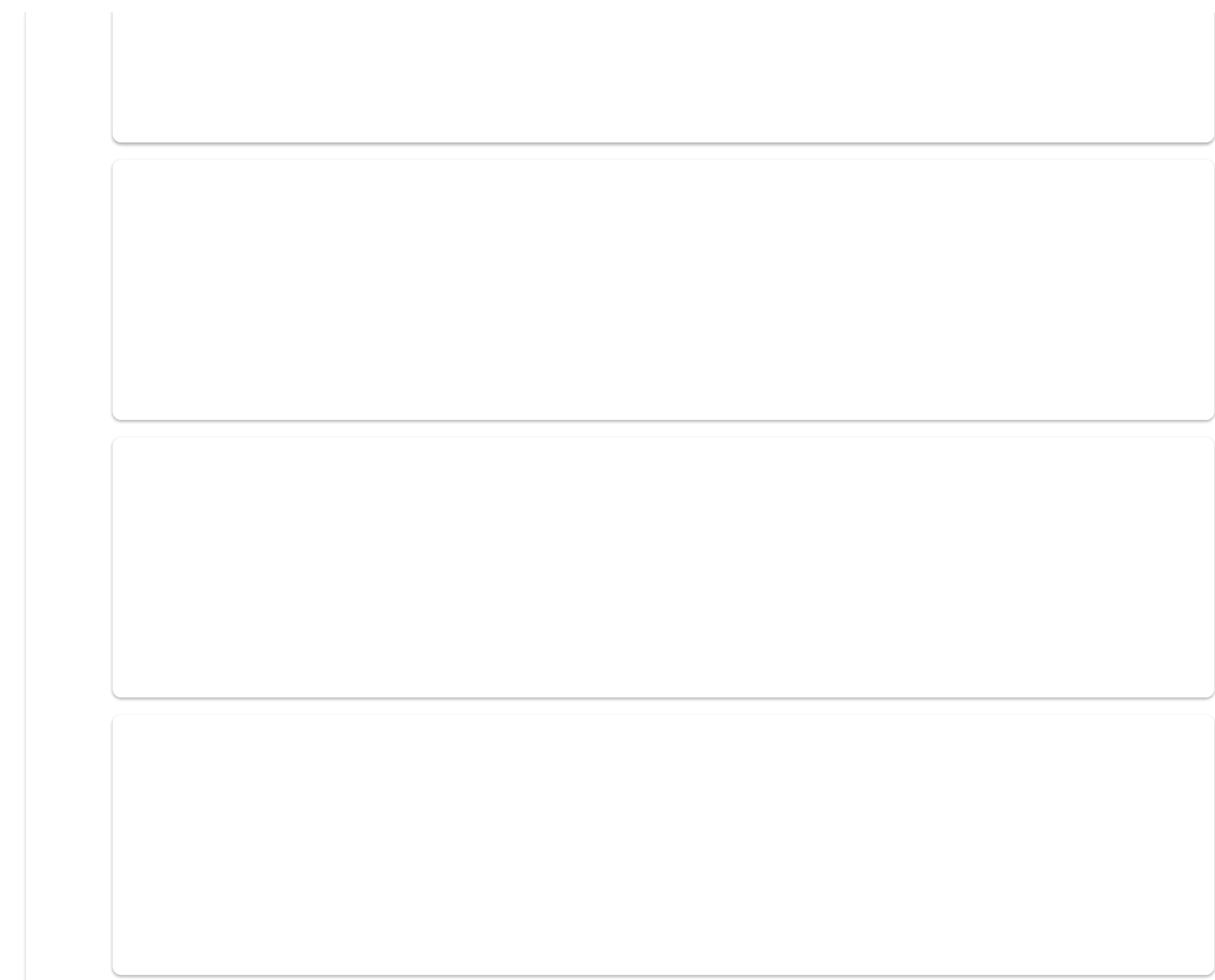


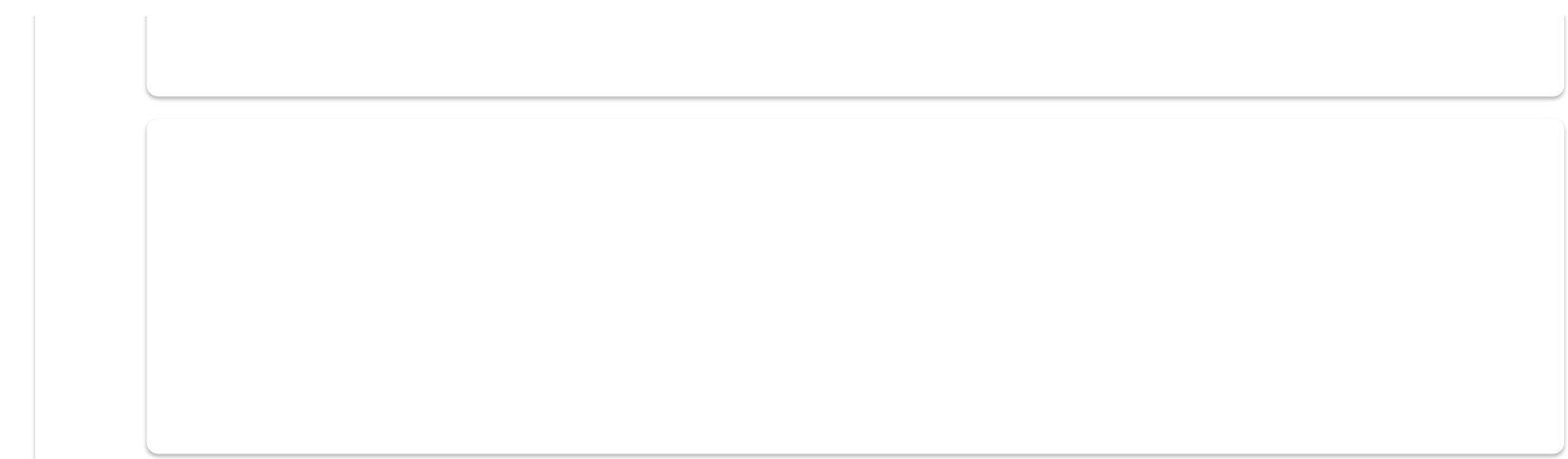




$\begin{array}{llll}\text { (c) 2021 Clarivate } & \text { Data Correction } & \text { Copyright Notice } & \text { Follow Us } \\ \text { Training Portal } & \text { Privacy Statement } & \text { Cookie Policy } & -\boldsymbol{f} \\ \text { Product Support } & \text { Newsletter } & \text { Terms of Use }\end{array}$

